\title{
Team Members
}

U.S. TEAM

Christopher Klager

Tom Bielik

Deborah Peek-Brown

Israel Touitou

Kellie Finnie
FINLAND TEAM

Kalle Juuti

Janna Inkinen

Katja Upadyaya

Jukka Marjanen

Janica Vinni-Laakso

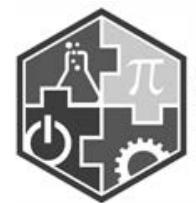

CRAFTING ENCAGEMENT FOR SCIENCE
ENVIRONMENTS

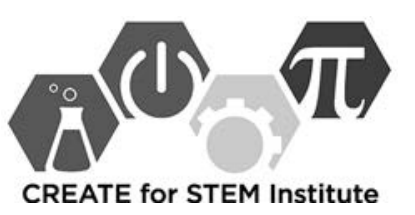

"Crafting Engagement for Science Environments" (CESE) is the name of the study for which we were funded by National Science Foundation and which is discussed in this book. The CESE logo appears on the reports, curriculum, and assessments that we send out to researchers, policymakers, and teachers.

CREATE for STEM at MSU is the name of the institute at Michigan State University under which CESE is housed. The CREATE acronym stands for Collaborative Research in Education, Assessment, and Teaching Environments; STEM for science, technology, engineering, and mathematics. During the course of our research they provided legal advice, psychometricians, science experts, science teacher educators, and assistance with automated analysis of constructed response (AACR) for analytic purposes. 
This page intentionally left blank 